\title{
13
}

\section{Avenues of Opportunity: Journeys of Activities Through Third Sector Organisations}

\author{
Angela Turner-Wilson, Stuart Dearborn, \\ and Catherine Bullen
}

\section{Introduction: Beyond Prisons}

The use of prison as a means of 'punishing' and 'correcting' those who have allegedly committed a crime against society is open to debate. Indeed, the benefits and problems of giving people a custodial sentence continue to rage in socio-economic and political domains across the globe. Retributive incarceration does remain popular in liberal democracies as well as totalitarian regimes, despite questions as to whether this

\footnotetext{
A. Turner-Wilson $(\varangle)$ Bournemouth, UK

e-mail: aturnerwilson@bournemouth.ac.uk

S. Dearborn

The Footprints Project, Poole, UK

e-mail: stuart@footprintsproject.co.uk

C. Bullen

Wiltshire Health and Care, Salisbury, UK

Department of Medical Science and Public Health, Bournemouth University, 
is the right approach (Jordan, 2003; Scott, 2013). One field of interest that has tried to move beyond this lies in restorative justice, which has, over the last few decades, become popular, especially in Europe and Scandinavia. It has been defined as a "process whereby parties with a stake in a specific offence collectively resolve how to deal with the aftermath of the offence, and its implications for the future" (Marshall, 1996, p. 37). It places emphasis on conflict resolution and societal responsibilities (Cunneen \& Goldson, 2015). In Norway, for example, it can be related to practices that prioritise the importance of the welfare system for those in prison and during resettlement. As such third sector organisations (TSOs) play a part. These not-for-profit, voluntary agencies (sometimes referred to as non-governmental organisations or NGOs) are neither public nor private (National Audit Office, 2019) and are part of the world of rehabilitation, change and decriminalisation. In many countries, they are crucial in the complex world of the 'afterwards', the time when someone who has been released from prison is working towards reintegrating back into society. However, this period has no clear end date and restorative justice is, as Crawford (2015) has argued, 'Janusfaced' as it asks those involved to be simultaneously looking backwards and forwards across time.

\section{Third Sector Organisations and the Criminal Justice Service}

A number of authors have discussed the role of TSOs in relation to ex-prisoners. Some have considered how TSOs support those released from prison who have immediate needs such as housing (Mills et al., 2013; Ellison et al., 2013) or require help with physical and psychological issues such as self-harming behaviours (National Institute for Health Research UK, 2020). Others have explored how TSOs are involved in assisting older or younger individuals, or those with learning difficulties (Forsyth et al., 2017; Acar \& Tekin, 2011; Kelly et al., 2012). In respect to restorative justice, there are discussions about the role of TSOs in the provision of support for victim and offender mediation, such as Lo's (2019) dissertation thesis concerning this work in Hong Kong. 
Wider more general insight into TSOs is slightly less common, although papers such as Kaufman (2015) delve into the importance of these institutions as places that deepen citizenship for ex-prisoners. This chapter contributes to this corpus of material by considering TSOs from a very specific person-centred lens. It asks what TSOs might offer, what are their benefits, their challenges and can they really contribute to change and opportunities for ex-prisoners after they are released?

We gain some answers to these questions through insights from work undertaken by an individual called Roger (not his real name), who had joined a team of researchers on a European funded grant whose mission was to optimise collaboration and integration between criminal justice and health and welfare services across the European Union (EU). Roger had been in contact with the criminal justice system, but was now employed in a not-for-profit organisation in the UK. One of his contributions to the study, along with colleagues, was to travel through different regions of Norway to explore and document interagency practices. This work offers insights based on this journey.

\section{Social Anthropology and Ethnography}

Given the focus of this work, an anthropological approach offered a sound theoretical fit. Social anthropology considers areas such as laws, social control, kinship and symbolism to name but a few (e.g. see Hendry, 2016). It is a philosophy that can provide a "direct immersion in a culture" with, "field experiences (that are) focused not so much by formal research methods, as by the unique talents and interests of the anthropologists..." (Haines, 2017, p. 3) and one might add this can include all who utilise ethnographic frameworks. The use of ethnography in seeking to understand prisoners is not new, see for example Drake et al's. (2015) edited book. One contributor to this text, Hammersley (2015, p. 27) has argued that ethnography is about, "producing 'closeups' of social phenomena". To achieve this, postmodernist perspectives can be useful. 


\section{Context and Place}

Traditionally anthropology concerned itself with undertaking detailed studies of culture within single sites (e.g. see Van Maanan, 2011). This approach was sometimes based on the search for 'universal truths', an idea rejected by postmodernist factions. Lyotard (1984, p. xxiv), for instance, famously stated that he had an "incredulity toward metanarratives". Unlike the empirical generalist perspectives, postmodernism is about deconstructing world views. Within anthropology, it offered approaches that included working on multilocal projects which included interdisciplinary (Marcus, 1995) or even interpersonal insights. It could create a "translocal network of relationships" (Hannerz, 2003, p. 209). Bearing this latter point in mind, the field visits for this study involved different locations, but they were all part of one country, in this case, Norway. The team went to the City of Oslo, Stavanger in Rogaland, Molde in Møre og Romsdal, Bergen in Vestland, and Tromsø in Troms og Finmark. These are all towns and were selected as $80 \%$ of people live in the major cities in Norway (World Population Review, 2020). However, they did offer different regional perspectives, and importantly several TSOs are based in these areas.

TSOs usually act as formal and, or informal community groups that seek to meet their users' needs, but they are not immune to criticism. It has been suggested, for instance, that they should be more evidenced based (e.g. see Jardine \& Whyte, 2013). Whilst this is a debate beyond the scope of this work, one area that TSO might look to in order to address these concerns lies in organisational learning. This is a concept by which organisations drive knowledge creation, which can, in turn, lead to innovation and new ways of thinking (Wang \& Ahmed, 2003). It is an approach that can contribute to effective practice. Organisational learning has an underpinning philosophy of shared visions and team working (Retna, 2006), especially important when thinking about how networks, relationships and common goals come together (Teeters \& Jurow, 2018). Organisational learning is about context and place, but it also speaks to people who are inside and, or outside specific communities. 


\section{Self and Other}

So, it was not just the concept of place that matters in this work, for as McGarry and Mannik (2017, p. 76) note, "for anthropologists, the focus is on dialogic anthropology. In other words, anthropologists view the production of knowledge as always taking place within an interaction, so meaning is relational". Ethnography has also been about the etic (outsider) and emic (insider) perspectives, concepts, which have been discussed in this field for many years (Olive, 2014). Roger, the key protagonist in this narrative, slid between the etic and emic. He was for example, a researcher, a professional and, in addition, someone who had experienced prison first-hand. It could be argued that this research was, "part of (a) reality that (co-) generates and (co-) constructs socially" Flick (2014, p. 4), and one that celebrates the standpoint of 'the outsider within' (Adler \& Adler, 2008, p. 17).

Working in anthropological studies and travelling to different locations are not without its challenges for the self. Issues such as 'adverse incorporation' (societal mechanisms that seek to keep people in disadvantaged situations) (Khan et al., 2015) may still be present, especially for researchers such as Roger. They may encounter social boundaries defined as "objectified forms of social differences, manifested in unequal access to and unequal distribution of resources (material and non-material) and social opportunities" (Lamont \& Molnár, 2002, p. 168). Challenges that are not unfamiliar to those who have been incarcerated.

\section{Capturing Insights}

As Marcus (1995, p. 97) notes, "strategies of quite literally following connections, associations, and putative relationships are....at the very heart of designing multi-sited ethnographic research". With ethical agreements in place, this is the approach used by Roger and his colleagues. They used 'jottings' which were deemed to be the best option as it allowed everyone to capture their life-world views on the spot (Bernard, 2011). Their notes formed reflective narratives of the self and other within the storytelling of the third sector. 


\section{Modes of Analysis}

Written narratives provide a means to capture reflections. They can act as a way of finding meaning in the human experience (Lee et al., 2004). Yet there are complexities within narrative analysis and ethnography as Gubrium and Holstein (1999, p. 570) highlight, "what is conveyed" in storytelling is "circumstantially consequential for both the storyteller and his or her audience". There is, they continue, a degree of 'authorial' narratives which bind the informants' accounts into contextual understandings. In relation to this project once the field notes were complete Roger and the team reviewed the narratives seeking patterns of commonality and variation through constant readings and comparison (Silverman, 2000). Coding was undertaken to support this.

Jones and Watt (2010, p. 163) remind us that, "ethnography without a theoretical framework is just description", but they also note that all data has something to say, and it is still the researchers who consciously or unconsciously prioritise and edit the material. Therefore, when we consider this study's findings and discussions they are tied to these principles. For example, Roger used a loose term, 'activities' to describe the many and varied opportunities that ex-offenders can participate in within the third sector.

\section{Insights and Discussion}

Five key themes emerged from the analysis. These were:

- Outdoor opportunities

- Community opportunities

- Hidden opportunities

- Social boundary crossing opportunities

- Organisational learning opportunities. 


\section{Outdoor Opportunities}

It is recognised that contact with the outdoors has positive health benefits. The literature is rich within this field. Barnes et al. (2019), for example, noted that contact with nature enhances mental health, selfesteem and cognitive functioning and that these affects appear to cross different groups and populations. A number of TSOs both in the UK and Norway offer outdoor-related activities for their service users. This is important as long periods of incarceration in a prison setting (such as those held in high security) can create what has been termed nature deficit, and whilst work has been done to try to overcome this, such as the use of Moss-in-Prisons project in the US (prisoners collecting and caring for different types of moss) (Nadkarni, 2017), it does not fully address the need. This is where the TSOs can help.

Roger and his research colleagues noted that the link between person and outside is especially strong in Norway, where the idea of being outdoors for leisure purposes is very much part of their culture. One third sector organisation offered over 50 different activities. Howe (2019) noted that the 'friluftsliv' (a Norwegian term) relates to the self within nature. Its meaning is broad and can be used to describe undertaking outdoor sports like football, mountaineering or just going for a simple walk. Indeed, many towns in Norway have parks, often at their centre, such as those in Bergen, Olso or Stavanger.

Interestingly Roger and the team noticed that 'bad' weather such as rain or snow appeared to have no effect on participation in the outdoor activities offered by TSOs in Norway. The underlying philosophy in this country appears to be that as long as the correct clothing is worn, the weather poses no obstacle to outdoor life ('Det finnes ikke dårlig vær, bare dårlige klær') and in fact, it can even help one feel positive about life generally (Bourrelle, 2018). So, despite the weather, some of the TSOs in Norway noted that there was a waiting list for people to apply to join. A popular walking area for many who wish to engage with nature is a path that leads almost directly from one of the TSOs offices in Bergen up towards Mount Floyen.

Although positive, it is worth noting that there is a cost to providing access to many of these activities. The hire of halls, the price of the 
'right' clothing, the fees for pieces of sports kits and so forth are not cheap. This represents the more problematic side for the not-for-profit societies who can often struggle to find funds. Roger and his colleague noted that in some TSOs, service users are asked to pay a fee if they wish to participate in activities. This can, for some, be a challenge. Poverty for those who have been in contact with the CJS is very real. As one former UK prisoner stated, "the prison sentence does not end when the prison gates open" (Foster, 2017). For example, in the UK a person is currently given $\mathfrak{£} 46.00$ release grant to supposedly see them through until they can obtain government-provided benefits (usually at least 6 weeks) or get a job. However, the benefits system is fraught with difficulties and obtaining paid work can be hard. Therefore, a severe lack of money can constrain not only those released from prison but can also affect those who seek to support them back into society.

\section{Community Opportunities}

Apart from promoting activities in the outdoors, TSOs also provide a lot of social support. They offer, for example, regular sessions for people to meet with others, potentially useful for those who have completed a custodial sentence and are looking to find comradeship and re-engagement with society. In addition, many offer signposting to vital services such as places that offer accommodation (although sometimes this is only very short term), healthcare, food banks and access to clothing. Some also provide individual appointments to discuss ways forward such as how to re-enter the job market. This was the case, for example, with the Red Cross in Tromsø. Although not directly in the town centre it was reasonably easy to access for those able to walk. It could be identified by the presence of the Red Cross flag outside.

On his journey, Roger chatted to two colleagues in Norway who acted as peer supporters within a TSO. Roger noted that they stated they were always welcome to go back to the service where they were clients, and some do opt to become volunteers. In a survey of 23 countries, it was found that people were more likely to undertake voluntary work in countries such Norway (67\% in their case), Austria and Switzerland, but this 
figure was much lower in countries such as the UK, Russia, Poland and Bulgaria (Huppert et al., 2009). Whilst not specifically representing exprisoner volunteers, this is, nevertheless, interesting. Embedded into the social world in Norway is an understanding that helping and building capacity within your local community matters. Simon and Mobekk (2019, p. 815) note that "the term 'dugnad' (a Norwegian word) refers to a sort of voluntary work done as a community or collective. Traditionally, 'dugnad' is a way of solving local common tasks by means of collective efforts from the community". These authors continue, "voluntary organisations (in Norway) adopted 'dugnad' as they emerged in the nineteenth century". In light of this, it might be suggested that those using TSOs may feel more at ease volunteering and tapping into different steams of social support, compared to those from other countries. This is important as acting in a voluntary capacity can improve a sense of shared social identity and enhances feelings of wellbeing (Gray \& Stevenson, 2019) which can be helpful for those who have been in prison.

Special holidays are common in many countries throughout the world. Norway is famous for a festival known as Constitution Day celebrated on 17th May. Whilst the day has a strong focus on children, it also provides the adults with an opportunity to dress in their local national costumes. The festivities are not only confined to Norway, as celebrations also occur in other countries that have immigrant Norwegian people, such as the US, Canada and Russia. The wearing of the 'bunad' in Norway (their national costume) creates a collective identity, although there are many variations of the clothing. Those seeking to link with TSOs at this time will almost inevitably be caught up with these celebrations. So, whilst it is an excellent opportunity to mix with friends and family, it may also, occasionally, highlight difference (though that is not its intension). TSOs can be helpful at these times when, perhaps ex-prisoners may feel a sense of otherness, the outsider, the stranger in the crowd. 


\section{Hidden Opportunities}

Some not-for-profit associations support individuals with addictions to, for instance, alcohol, gambling and drugs. Those attending may have had a custodial sentence, but this is not always the case. These organisations may offer support meetings and a safe place to talk. Sometimes these meetings are closed to anyone who is not part of the group to ensure anonymity. Roger had been in contact with these services in the UK and was therefore also comfortable in making links through these routes internationally. However, meetings were not open to the rest of the research team. Roger reported that many opportunities existed for ex-prisoners which were highlighted during some of these meetings, but this information was generally only shared amongst the groups. Nevertheless, it is worth noting that members from these associations, such as narcotics anonymous (see Narcotic Anonymous World Services, 2020) provide educational talks and presentations to professionals, academics and others, and by doing so create a bridge between their world and the wider society.

Continuing the theme of hidden opportunities many countries offer 'free' activities. For example, in Oslo, there is a large sculpture park, Vigeland, which is open to all and has over 200 full-size statues of people from all age groups often in active stances. They represent life, and many emotions are captured ranging from happiness to anger, from love to despair.

The importance of art in prisons is well recorded (e.g. see Mayou's [2016] discussion about a collection of objects made by prisoners in countries which have experienced violent times such as Chile, Vietnam, Yugoslavia, Algeria to Afghanistan and Rwanda), but there is sometimes less emphasis placed on third sector inputs and outputs. Rafter (2014, p. 129) offers an interesting insight into the world of visual criminology. He says it is, "the study of ways in which all things visual interact with crime and criminal justice, inventing and shaping one another". One might argue that places such as Vigeland provide this. For example, one statue placed along the bridge that enters the park depicts a man with outstretched arms reaching for the sky that may speak of success. Parks such as Vigeland can be seen as settings that offer those in the 'afterwards' 
spaces to view, to contemplate, to reposition their ideas and thoughts on humanity within their own life-worlds.

Of course, sculptures can be seen in many urban locations. A lifesized bronze statue of a young girl stands by the door of a Mcdonald's restaurant in Bergen. This is a place which offers reasonably priced hot drinks and meals in a warm comfortable setting. Roger visited this location during this study. It may be proposed that the presence of art at places such as fast-food restaurants addresses the inclusivity for viewing this medium.

In addition, there are many examples of free places to visit in urban and rural settings, such as parks, botanical gardens and outdoor gyms. Local communities also sometimes run free events such as music or art festivals. An interesting example of free art lies in a Banksy-type piece of work found on the wall of an unassuming building in Tromsø. It is a picture of a little girl with a bucket and spade. The sun is shining above, her shadow is clearly visible. However, when viewed in the winter this seaside scene is juxtaposed with the heavy snow on the pavement in front of the art, a regular occurrence in a town that lies within the Arctic Circle. The viewer of this image is invited into summer, even in the darkest of days. The Polar night in Tromsø occurs from November to January when the sun does not rise, and it is recognised that light matters within Norwegian culture. It can be argued that the picture of the little girl on the wall represents hope, especially important for those on the margins of society who cannot travel elsewhere to seek sunlight.

There are then activities and things to see and do in urban settings, but these are not always celebrated for their social and therapeutic benefits, especially for those seeking to re-establish themselves after being in custody. Whilst not all are run by TSOs, they act as TSO opportunities, and can therefore be said to be a little bit more hidden.

\section{Social Boundary Crossing Opportunities}

Roger had joined this research team with enthusiasm which never waned, and indeed the importance of community-engaged research is increasingly recognised as beneficial to a research study (Page-Reeves \& Regino, 
2018). The very act of undertaking this work and engaging with TSOs meant Roger crossed a variety of social boundaries. It is not uncommon for individuals such as Roger to suffer stigmatisation by those in society who think they are not to be trusted and label them with names such as ex-offenders, addicts and criminals. Indeed, those who have been in contact with the CJS are sometimes perceived to have deficiencies in education, knowledge and skills (Pogrebin et al., 2014). Yet Roger was able to overcome this. He was of course already employed, a considerable achievement since many from disadvantaged groups often struggle to even become volunteers within societal groups (for example see Southby \& South, 2019). Nevertheless, Roger successfully navigated his way through the complexities of multiple organisations. He was an agile thinker adapting to the different situations that arose as a result of the research study. He became an international representative who was comfortable discussing his work on a more scholarly platform. In a sense, the research project and visits to the third sector hubs acted as a change agent for Roger, and indeed for those who worked alongside him. The life-world experiences encountered by all shifted, altered and changed everyone's realities. In relation to a peer supporter Roger met in the Red Cross in Norway he said,

I was interested in one of the things one of these guys said, he said he has a new identity, meaning his new way of life has brought him a new identify from his old life of crime and drug use. And part of him staying on the right path for him is helping others join in the activities to help their confidence and help them become part of the activity.

\section{Organisational Learning Opportunities}

Roger, along with his research colleagues, shared their own perspectives and insights with the service users, volunteers, paid employees that they met on this journey, and they, in turn, reciprocated. As we have seen, the ideas and cultural insights that emerged were holistic and did not take a single perspective. These diverse, but important pieces of knowledge supported the idea of organisational learning. As an example, Roger 
had recognised the importance of outdoor and social activities for exprisoners, and on his return to the UK from Norway he looked for opportunities to further incorporate this within the TSO. One of Roger's proposals involved improving in-house training for volunteers in whatever activity they were interested in (within reason). This would expand choice for service users and provide further knowledge, skills and deeper social engagement for everyone involved. The approach had the added benefit of TSO working more collaboratively with businesses and others (some who may be able to provide additional funding) who may not traditionally link with those who have been in contact with the CJS. Boundary crossing may occur, and all could learn in what Roger called 'building togetherness'. Of course, as Roger highlighted, data collected ethically and sensitively (via, for instance, group discussions, one to one sessions, or even from a family member reporting a positive change in their significant other) could further inform the direction of the activities and whether improvements or changes could or should be made. Feedback on success could be shared with those in the wider community through, for example, presentations, radio advertising, newsletters, magazines and social media. New communities of practice (groups comprised of members from outside the traditional professional or organisational boundaries) adopting a "shared repertoire" (Hughes et al., 2007, p. 4) could develop as a result of such initiatives with each building new cells in an ever increasing honeycomb of collaborative work. This could, in turn, have the potential to influence local policymakers and divert funding streams towards TSOs.

\section{Conclusion}

This work highlights the importance of the third sector and their role for ex-prisoners. The narratives embedded within postmodern ethnography discuss and reflect how different activities might contribute to the physical, psychological and social wellbeing of those who have had contact with the CJS. The strands of opportunities are opened-up further with insights from different international perspectives, especially those between Norway and the UK. It is also recognised that the research 
journey was, itself, a contributing factor to widening opportunities, noted in the text on social boundary crossing. However, and importantly, the smorgasbord of ideas that emerge from this ethnographic work demonstrates that ideas and thoughts can be shared and organisational learning, in all its variants, can take place often naturally and seamlessly. Indeed, this work highlights that different TSOs and those outside this sphere can learn not only from each other, but also from the wider society. Through these glimpses from Roger and his colleagues, it is clear that TSOs deserve much more attention from researchers, academics, professionals, business leaders, politicians, ex-prisoners and their families as these places play such a key role in supporting those who find themselves lost in the 'afterwards'.

\section{References}

Acar, Y. B., \& Tekin, U. (2011). The roles of non-governmental organizations in German youth justice and assistance system: Cologne model. Review of International Law \& Politics, 7(25), 205.

Adler, P. A., \& Adler, P. (2008). Of rhetoric and representation: The four faces of ethnography. Sociological Quarterly, 49(1), 1-30.

Barnes, M. R., Donahue, M. L., Keeler, B. L., Shorb, C. M., Mohtadi, T. Z., \& Shelby, L. J. (2019). Characterizing nature and participant experience in studies of nature exposure for positive mental health: An integrative review. Frontiers in Psychology, 9. https://doi.org/10.3389/fpsyg.2018.02617.

Bernard, H. R. (2011). Research methods in anthropology (5th ed.). London: Rowman \& Littlefield.

Bourrelle, J. S. (2018). The social guidebook to Norway (3rd ed.). Mondå Forlag. Crawford, A. (2015). Temporality in restorative justice: On time, timing and time-consciousness. Theoretical Criminology, 19(4), 470-490. https://doi. org/10.1177/1362480615575804.

Cunneen, C., \& Goldson, B. (2015). Restorative justice? A critical analysis. In B. Goldson \& J. Muncie (Eds.), Youth, Crime and Justice (2nd ed.) (pp. 137-156). London: Sage.

Drake, D. H., Earle, R., \& Sloan, J. (Eds.). (2015). The Palgrave handbook of prison ethnography. Basingstoke: Palgrave Macmillan. 
Ellison, M., Fox, C., Gains, A., \& Pollock, G. (2013). An evaluation of the effect of housing provision on re-offending. Safer Communities, 12(1), 27. https://doi.org/10.1108/17578041311293125.

Flick, U. (2014). The Sage handbook of qualitative data analysis. London: Sage. Forsyth, K., Archer-Power, L., Senior, J., Meacock, R., Webb, R., \& Emsley, R., et al. (2017). The effectiveness of the older prisoner health and social care assessment and plan (OHSCAP): A randomised controlled trial. Health Services and Delivery Research, 5(31). https://doi.org/10.3310/hsdr05310.

Foster, R. (2017, August 10). What happens when you finally get released from jail? One former prisoner explains. Metro. https://metro.co.uk/2017/ 08/10/what-happens-when-you-finally-get-released-from-jail-one-former-pri soner-explains-6831114/. Accessed 27 June 2020.

Gray, D., \& Stevenson, C. (2019). How can 'we' help? Exploring the role of shared social identity in the experiences and benefits of volunteering. Journal of Community and Applied Social Psychology, 1-13. https://doi.org/10.1002/ casp. 2448.

Gubrium, J. F., \& Holstein, J. A. (1999). At the border of narrative and ethnography. Journal of Contemporary Ethnography, 28(5), 561-573.

Haines, D. W. (2017). An introduction to sociocultural anthropology: Adaptations, structures, meanings (2nd ed.). Boulder: University Press of Colorado.

Hammersley, M. (2015). Research 'inside' viewed from 'outside': Reflections on prison ethnography. In D. H. Drake, R. Earle, \& J. Sloan (Eds.), The Palgrave handbook of prison ethnography (pp. 21-39). Basingstoke: Palgrave Macmillan.

Hannerz, U. (2003). Being there ... and there ... and there! Reflections on multi-site ethnography. Ethnography, 4(2), 201-216.

Hendry, J. (2016). An introduction to social anthropology: Sharing our worlds (3rd ed.). Basingstoke: Palgrave Macmillan.

Howe, L. A. (2019). Not everything is a contest: Sport, nature sport, and friluftsliv. Journal of the Philosophy of Sport, 46(3), 437-453. https://doi. org/10.1080/00948705.2019.1622126.

Hughes, J., Jewson, N., \& Unwin, L. (2007). Introduction. Communities of practice: A contested concept in flux. In J. Hughes, N. Jewson, \& L. Unwin (Eds.), Communities of practice: Critical perspectives (pp. 1-16). Abingdon: Routledge.

Huppert, F. A., Marks, N., Clark, A., Siegrist, J., Stutzer, A., \& Vittersø, et al. (2009). Measuring well-being across Europe: Description of the ESS wellbeing module and preliminary findings. Social Indicators Research, 91(3), 301-315. https://doi.org/10.1007/s11205-008-9346-0. 
Jardine, C., \& Whyte, B. (2013). Valuing desistence? A social return on investment case study of a throughcare project for short-term prisoners. Social and Environmental Accountability Journal, 33(1), 20. https://doi.org/10.1080/ 0969160x.2013.768088.

Jones, J. S., \& Watt, S. (2010). Making sense of it all. In J. S. Jones \& S. Watt (Eds.), Ethnography in social science practice (pp. 157-172). Abingdon: Routledge.

Jordan, B. (2003). Criminal justice, social exclusion and the social contract. Probation Journal, 50(3), 198-210. doi: 0264-5505(200309)50:3;198210;035887.

Kaufman, N. (2015). Prisoner incorporation: The work of the state and non-governmental organizations. Theoretical Criminology, 19(4), 534-553. https://doi.org/10.1177/1362480614567172.

Kelly, J., Collier, A., \& Stringer, J. (2012). Providing a learning disability inreach service for young adult offenders serving a sentence of Imprisonment for Public Protection. Journal of Learning Disabilities \& Offending Behaviour, 3(3), 139-149. https://doi.org/10.1108/20420921211305882.

Khan, S., Combaz, E., \& McAslan Fraser, E. (2015). Social exclusion: Topic guide (Revised Edition). https://gsdrc.org/wp-content/uploads/2015/08/Soc ialExclusion.pdf. Accessed 27 June 2020.

Lamont, M., \& Molnár, V. (2002). The study of boundaries in the social sciences. Annual Review of Sociology, 28, 167-195. https://doi.org/10.1146/ annurev.soc.28.110601.141107.

Lee, C. D., Rosenfeld, E., Mendenhall, R., Rivers, A., \& Tynes, B. (2004). Cultural modelling as a frame for narrative analysis. In C. Daiute \& C. Lightfoot (Eds.), Narrative analysis: Studying the development of individuals in society (Chapter 1.3, pp. 38-39). London: Sage.

Lo, H.-K. (2019). Restorative justice and Confucianism in Hong Kong. http:// eprints.mdx.ac.uk/26455/. Accessed 27 June 2020.

Lyotard, J.-F. (1979). La condition postmoderne: rapport sur le savoir. Les Editions de Minuit. English edition: Lyotard, J.-F. (1984). The postmodern condition: A report on knowledge (G. Bennington \& B. Massumi, Trans.). Manchester: Manchester University Press.

Marcus, G. E. (1995). Ethnography in/of the world system: The emergence of multi-sited ethnography. Annual Review of Anthropology, 24(1), 95-117.

Marshall, T. (1996). The evolution of restorative justice in Britain. European Journal on Criminal Policy and Research, 4(4), 21-43. https://doi.org/10. 1007/BF02736712. 
Mayou, R. (2016). Prisoners' objects: The collection of the International Red Cross and Red Crescent Museum. International Review of the Red Cross, 98(3), 749-760. https://doi.org/10.1017/s1816383117000595.

McGarry, K. A., \& Mannik, L. (2017). Practicing ethnography: A student guide to method and methodology. Toronto: University of Toronto Press, Higher Education Division.

Mills, A., Gojkovic, D., Meek, R., \& Mullins, D. (2013). Housing exprisoners: The role of the third sector. Safer Communities, 12(1), 38. https:// doi.org/10.1108/17578041311293134.

Nadkarni, N. (2017). Branching out. In T. L. Fleischner (Ed.), Nature, Love Medicine (pp. 27-40). Torrey, UT: Torrey House Press.

Narcotic Anonymous World Services. (2020). Welcome to www.NA.org. https://na.org/. Accessed 27 June 2020.

National Audit Office. (2019). What are third sector organisations and their benefits for commissioners? https://www.nao.org.uk/successful-commissio ning/introduction/what-are-civil-society-organisations-and-their-benefitsfor-commissioners/. Accessed 27 June 2020.

National Institute for Health Research, U. K. (n.d.). (2020). Skin camouflage for women prisoners with self-harm scarring (COVER). https://clinicaltrials. gov/show/NCT02638974. Accessed 27 June 2020.

Olive, J. L. (2014). Reflecting on the tensions between emic and etic perspectives in life history research: Lessons learned. Forum: Qualitative Social Research, 15(2), Art 6.

Page-Reeves, J., \& Regino, L. (2018). Community-university health research partnerships: Challenges and concrete, plain language strategies for community engagement in research. Anthropology in Action, 25(2), 1-12. https:// doi.org/10.3167/aia.2018.250202.

Pogrebin, M., West-Smith, M., Walker, A., \& Unnithan, N. P. (2014). Employment isn't enough: Financial obstacles experienced by ex-prisoners during the re-entry process. Criminal Justice Review, 4, 394-410. https://doi.org/ $10.1177 / 0734016814540303$.

Rafter, N. (2014). Introduction to special issue on visual culture and the iconography of crime and punishment. Theoretical Criminology, 18(2), 127-133. https://doi.org/10.1177/1362480613510547.

Retna, K. S. (2006). The learning organisation. International Journal of Learning, 13(1), 95-101. https://doi.org/10.18848/1447-9494/cgp/v13i01/ 48178.

Scott, D. (Ed.). (2013). Why prison? Cambridge: Cambridge University Press. 
Silverman, D. (2000). Doing qualitative research: A practical handbook. London: Sage.

Simon, C., \& Mobekk, H. (2019). Dugnad: A fact and a narrative of Norwegian prosocial behavior. Perspectives on Behavior Science, 42, 815-834. https://doi.org/10.1007/s40614-019-00227-w.

Southby, K., \& South, J. (2019). A rapid review of barriers to volunteering for potentially disadvantaged groups and implications for health inequalities. VOLUNTAS: International Journal of Voluntary and Nonprofit Organizations, 30(5), 907-920. https://doi.org/10.1007/s11266-019-00119-2.

Teeters, L. A, \& Jurow, A. S. (2018). Relationships de Confianza and the organisation of collective social action. Ethnography \& Education, 13(1), 84-99. https://doi.org/10.1080/17457823.2016.1271992.

Van Maanan, J. (2011). Tales of the field (2nd ed.). Chicago: University of Chicago Press.

Wang, C. L., \& Ahmed, P. K. (2003). Organisational learning: A critical review. The Learning Organisation, 10(1), 1-21. https://doi.org/10.1108/096964 70310457469.

World Population Review. (2020). Norway population 2020. https://worldpopu lationreview.com/countries/norway-population/. Accessed 27 June 2020.

Open Access This chapter is licensed under the terms of the Creative Commons Attribution 4.0 International License (http://creativecommons.org/ licenses/by/4.0/), which permits use, sharing, adaptation, distribution and reproduction in any medium or format, as long as you give appropriate credit to the original author(s) and the source, provide a link to the Creative Commons license and indicate if changes were made.

The images or other third party material in this chapter are included in the chapter's Creative Commons license, unless indicated otherwise in a credit line to the material. If material is not included in the chapter's Creative Commons license and your intended use is not permitted by statutory regulation or exceeds the permitted use, you will need to obtain permission directly from the copyright holder.

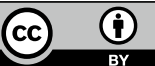

